\title{
Sistema: Palavras Indígenas
}

\author{
Dener G. Mendonça ${ }^{1}$, Joselice F. Lima ${ }^{1}$, Claudio A. Gusmão ${ }^{1}$, Suzana A. Escobar ${ }^{1}$ \\ ${ }^{1}$ Instituto Federal do Norte de Minas Gerais (IFNMG), Campus Januária-MG, Brasil \\ \{denerxy, joselice.f.lima, claudioagusmao, suza.escobar\}@gmail.com
}

\begin{abstract}
Resumo. Apresenta o Sistema Palavras Indígenas que colaborativamente auxilia na organização da escrita, da imagem e do som (pronúncia) das palavras indígenas contribuindo para sua preservação. Busca refletir sobre o uso da tecnologia em comunidades indígenas e o desafio de catalogar essas línguas. Como resultado as palavras indígenas antes repassadas verbalmente estarão disponíveis em formato de texto, imagem e som. Conclui-se que o sistema permitirá o armazenamento do vocabulário indígena contribuindo para seu resgate, preservação e compartilhamento.
\end{abstract}

\section{Cenário de uso}

Incluir digitalmente os indígenas à medida que aprendam e possam resgatar suas línguas é capacitá-los para que possam utilizar as tecnologias a seu favor e acima de tudo para que possam promover e defender sua identidade e em especial seu vocabulário, frente à crescente globalização. Neste contexto, o uso de recursos tecnológicos através do computador vem ganhando espaço em razão das facilidades proporcionadas pela internet $\mathrm{e}$ as redes sociais. Entretanto, dentro desta realidade, observa-se que a disseminação do conhecimento (língua indígena) é feita oralmente pelos índios. Os recursos de documentação, inclusive tecnológicos, são pouco utilizados como uma forma de armazenar a escrita da língua indígena e sua correta pronúncia. Diante disso indaga-se: - Como podemos organizar a escrita, a imagem e o som (pronúncia) das palavras indígenas contribuindo para sua preservação?

Este trabalho apresenta o Sistema Palavras Indígenas que colaborativamente auxilia na organização da escrita, da imagem e do som (pronúncia) das palavras indígenas contribuindo para sua preservação. Busca refletir sobre o uso da tecnologia em comunidades indígenas e o desafio de catalogar essas línguas. O sistema permite ao usuário aprender a língua indígena à medida que a cataloga. A relevância da ferramenta está em armazenar o vocabulário indígena e na possibilidade de ser utilizada em atividades escolares sejam elas de alfabetização, aulas de língua e cultura indígena, para inclusão digital de índios e muitas outras possibilidades e disciplinas para o qual o sistema possa ser utilizado.

\section{Desenvolvimento}

Foi adotada uma metodologia de desenvolvimento que pode ser definida como híbrida, mescla princípios de uma abordagem prescritiva com princípios das abordagens ágeis. Os requisitos foram amplamente levantados, analisados, projetados e documentados. Porém, na execução do projeto foi incorporado princípios de metodologias ágeis de desenvolvimento que prioriza essencialmente o feedback rápido e adaptação às mudanças de requisitos. Mediante as informações cadastradas, armazenadas e 
VIII Congresso Brasileiro de Informática na Educação (CBIE 2019)

Anais dos Workshops do VIII Congresso Brasileiro de Informática na Educação (WCBIE 2019)

trabalhadas no Sistema Palavras Indígenas, o mesmo pode ser caracterizado como um sistema de informação. Na visão de Oliveira (1999), "um sistema de informação é formado por subsistemas de informações que compreendem o planejamento e identificação de necessidades, a coleta, o tratamento, a análise e a validação da informação; divulgação, utilização e avaliação do seu uso (apud Mori, 2002, p. 21).”

No desenvolvimento de sistemas que são considerados "um conjunto de partes interagentes e interdependentes que, conjuntamente, formam um todo unitário com determinado objetivo e efetuam determinada função" (Oliveira, 2002, p. 35), são utilizadas várias ferramentas que possibilitam a integração dessas partes. Dentre as tecnologias usadas para o desenvolvimento de sistemas o Quadro 1 lista as ferramentas utilizadas no desenvolvimento do Sistema Palavras Indígenas.

\section{Quadro 1. Ferramentas de desenvolvimento}

\begin{tabular}{|l|l|}
\hline Ferramentas & Características/Detalhes \\
\hline PHP5 & $\begin{array}{l}\text { linguagem de script livre e gratuita, rápida, flexível e pragmática é } \\
\text { amplamente utilizada no desenvolvimento web. }\end{array}$ \\
\hline HTML5 & $\begin{array}{l}\text { linguagem de marcação usada para produzir páginas Web. É interpretado } \\
\text { pelos navegadores mais utilizados e serve como base para organizar os dados } \\
\text { exibidos na pagina web. }\end{array}$ \\
\hline CSS3 & $\begin{array}{l}\text { linguagem de estilização para códigos de marcação (HTML, XHTML). } \\
\text { Cascading Style Sheets (CSS) é um mecanismo simples para adicionar estilo } \\
\text { (fontes, cores, espaços) a documentos web. }\end{array}$ \\
\hline Javascript & $\begin{array}{l}\text { linguagem leve, orientada a objetos, mais conhecido como a linguagem de } \\
\text { script para páginas da Web. Suporta estilos de programação funcional } \\
\text { orientada a objeto. }\end{array}$ \\
\hline Bootstrap & $\begin{array}{l}\text { biblioteca de códigos CSS e Javascript que ao ser incorporado nas páginas } \\
\text { traz uma interface extremamente elegante e deixa tudo mais intuitivo dando } \\
\text { ao desenvolvedor mais agilidade e facilidade no desenvolvimento. }\end{array}$ \\
\hline Banco de Dados \\
MYSQL & $\begin{array}{l}\text { banco de dados de código aberto com bom desempenho, não requer grande } \\
\text { poder de processamento, é escalável, oferece confiabilidade e suporta varias } \\
\text { linguagens de programação. }\end{array}$ \\
\hline Servidor Web Apache & $\begin{array}{l}\text { servidor web de hospedagem de código aberto, disponibilizado gratuitamente, } \\
\text { relativamente seguro e fornece serviço em sincronia com os padrões HTTP. }\end{array}$ \\
\hline
\end{tabular}

Para a programação do sistema foi utilizado a plataforma NetBeans IDE $^{1}$, ele é um ambiente de desenvolvimento integrado (IDE) gratuito e de código aberto para desenvolvedores de sistema em diversas linguagens.

Para a gravação do som (pronúncia da palavra em indígena) optou-se pelo programa de gravação Audio Recorder For Free ${ }^{2}$. Por já existirem boas opções de programas de gravação de áudio no mercado, seria inviável buscar por outras soluções e implementações da gravação de áudio diretamente no sistema. O Audio Recorder For Free é um programa leve, fácil de usar e grava sons nos formatos MP3 e WAV.

\footnotetext{
${ }^{1}$ NetBeans IDE. Integrated Development Environment: https://netbeans.org/

${ }^{2}$ Audio Recorder For Free: https://audio-recorder-for-free.br.uptodown.com/windows
} 
A pesquisa e desenvolvimento do sistema se basearam pela natureza aplicada que visa a obtenção do conhecimento necessário para a geração de um produto (sistema) adequado as necessidades percebidas junto a determinado público (Gil, 2002; Jung, 2004). A observação, visita e conversas com indígenas foi realizada tendo por base e ambientação a comunidade indígena Xakriabá.

A etnia indígena Xakriabá está localizada no município de São João das Missões-MG e faz parte de uma das maiores comunidades indígenas de Minas Gerais. Os Xakriabá possuem uma história longa e complexa de seu contato com a sociedade nacional e, por consequência, vivem em interação com ela, sem terem sido, no entanto, assimilados e/ou dissolvidos no convívio. A população Xakriabá é estimada em 8.000 indígenas, distribuídos por várias aldeias e subaldeias, em 53.074,92 hectares de área, o que, em relação ao espaço humano e geográfico, equivale a mais de $70 \%$ da área e população do município de São João das Missões. Após o processo de contato, aconteceu o enfraquecimento da língua nativa desse povo, motivando os Xakriabá a adotarem como sua primeira língua o português (Escobar, 2012). Quanto à língua foram identificados pelo Handbook of South American Indians ${ }^{3}$ como Jê, subdivisão Akwén.

Quanto a validação do sistema, a aplicação de um teste de usabilidade é de suma importância, visto que, o feedback do usuário é necessário, a fim de analisar a capacidade de aprendizagem e uso sem dificuldades. Os testes com o público indígena dependem da autorização de lideranças indígenas Xakriabá, em contrapartida, visitas estão sendo feitas a fim de demonstrar a importância da pesquisa, avaliando a estrutura das escolas, centros de cultura e residências que possuem computadores e smartphones com acesso à internet. As palavras indígenas Xakriabá que estão no sistema foram coletadas através do ambiente web. Após o desenvolvimento do sistema o teste de usabilidade foi feito por um indígena, por um tecnólogo em sistema de informação e por um pedagogo que trabalha com as escolas estaduais indígenas Xakriabá.

\section{Apresentação do Software}

O Sistema Palavras Indígenas, busca oferecer uma alternativa tecnológica a ser empregada no auxílio à preservação de línguas indígenas, através do armazenamento de suas palavras (texto), imagem e pronúncia (áudio). Para isso apresenta uma ferramenta on-line, que permite ao usuário aprender a língua indígena à medida que a cataloga.

As informações cadastradas no sistema são a palavra em indígena (texto, imagem e som), seu sinônimo em português, além do cadastro da língua e do povo indígena. Um importante aspecto no sistema é a participação colaborativa dos usuários, que cadastram os dados relativos à constituição das informações. O Quadro 2 apresenta o tipo de participação dos envolvidos:

\footnotetext{
${ }^{3}$ Handbook of South American Indians: http://www.etnolinguistica.org/handbook:intro
} 
VIII Congresso Brasileiro de Informática na Educação (CBIE 2019)

Anais dos Workshops do VIII Congresso Brasileiro de Informática na Educação (WCBIE 2019)

\section{Quadro 2. Participação dos usuários no sistema}

\begin{tabular}{|l|l|}
\hline Usuários & Atividades e ou permissões no sistema \\
\hline Moderadores & $\begin{array}{l}\text { Alimentam o sistema cadastrando palavras, línguas e povos indígenas. Permitem a } \\
\text { entrada de novos Colaboradores. Transformam Colaborador em Moderador. }\end{array}$ \\
\hline Colaboradores & Alimentam o sistema cadastrando as palavras indígenas. \\
\hline Visitantes & $\begin{array}{l}\text { Acompanham as informações geradas pelo sistema à medida que os dados são } \\
\text { cadastrados pelos outros usuários. }\end{array}$ \\
\hline
\end{tabular}

Para maior segurança foi implementado Log de Dados, uma forma simples de gravar os eventos realizados pelos vários usuários dentro do sistema, facilitando a identificação de cada ação e possíveis eventualidades ou erros.

\subsection{A Visão do Sistema}

O Sistema Palavras Indígenas tem como proposta promover a integração do vocabulário indígena existente através do cadastro e armazenamento das palavras indígenas (texto), seu som (pronúncia) e sua imagem (identidade visual). $\mathrm{Na}$ existência de várias comunidades ou línguas indígenas é possível a vinculação de ambas no sistema o que permitiria uma comparação e integração entre as comunidades referente ao vocabulário utilizado, oferecendo assim uma maneira uniforme e centralizada de acesso.

Este sistema foi construído baseado na experiência linguística indígena tendo como base o cenário da comunidade Xakriabá, diante disso, a utilização via web, caracterizada por rápido carregamento da página, interface intuitiva e agradável atende a demanda apresentada nas comunidades indígenas. No desenvolvimento do sistema preocupou-se com as políticas de segurança e disponibilidade. Os princípios básicos da segurança da informção são apontados por Tanembaum 2003 (apud Scrócaro, 2013, p, 24), dentre eles a "Confidencialidade: propriedade que limita o acesso à informação tão somente às entidades legítimas, ou seja, àquelas autorizadas pelo proprietário da informação". No Sistema Palavras Indígenas o acesso às informações mais detalhadas referente as palavras, aos usuários, as línguas e aos povos acontece através de autenticação.

\subsection{Prática Demonstrativa}

Para incluir novas informações é necessário ser cadastrado no sistema. A participação é feita mediante solicitação e posterior aprovação por membros já cadastrados. Dentro deste contexto fica claro que o trabalho de participação no sistema e posterior inserção de dados visa contribuir para que apenas os usuários diretamente ligados a temática linguística indígena possam interagir na catalogação de tais palavras. A Figura 1 mostra a Tela Inicial do sistema com sua ideia central, armazenar e disponibilizar aos usuários as palavras indígenas que venham a ser cadastradas. 
VIII Congresso Brasileiro de Informática na Educação (CBIE 2019)

Anais dos Workshops do VIII Congresso Brasileiro de Informática na Educação (WCBIE 2019)

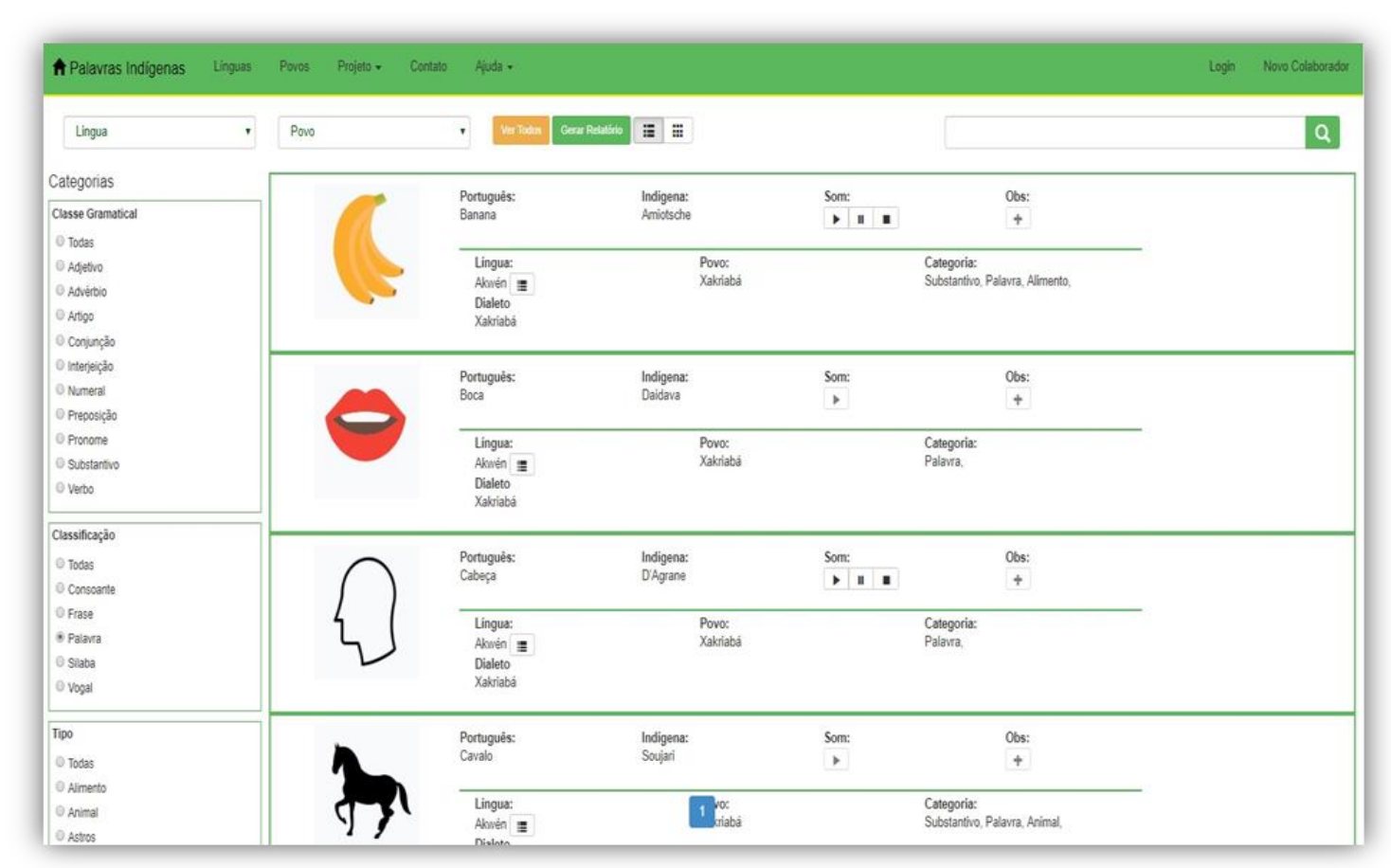

Figura 1. Tela Inicial; Palavras indígenas cadastradas (texto, imagem e som).

Inicialmente é cadastrada a palavra em português e em indígena referenciandose o povo e a língua. A Figura 2 mostra a tela de cadastro das palavras indígenas.

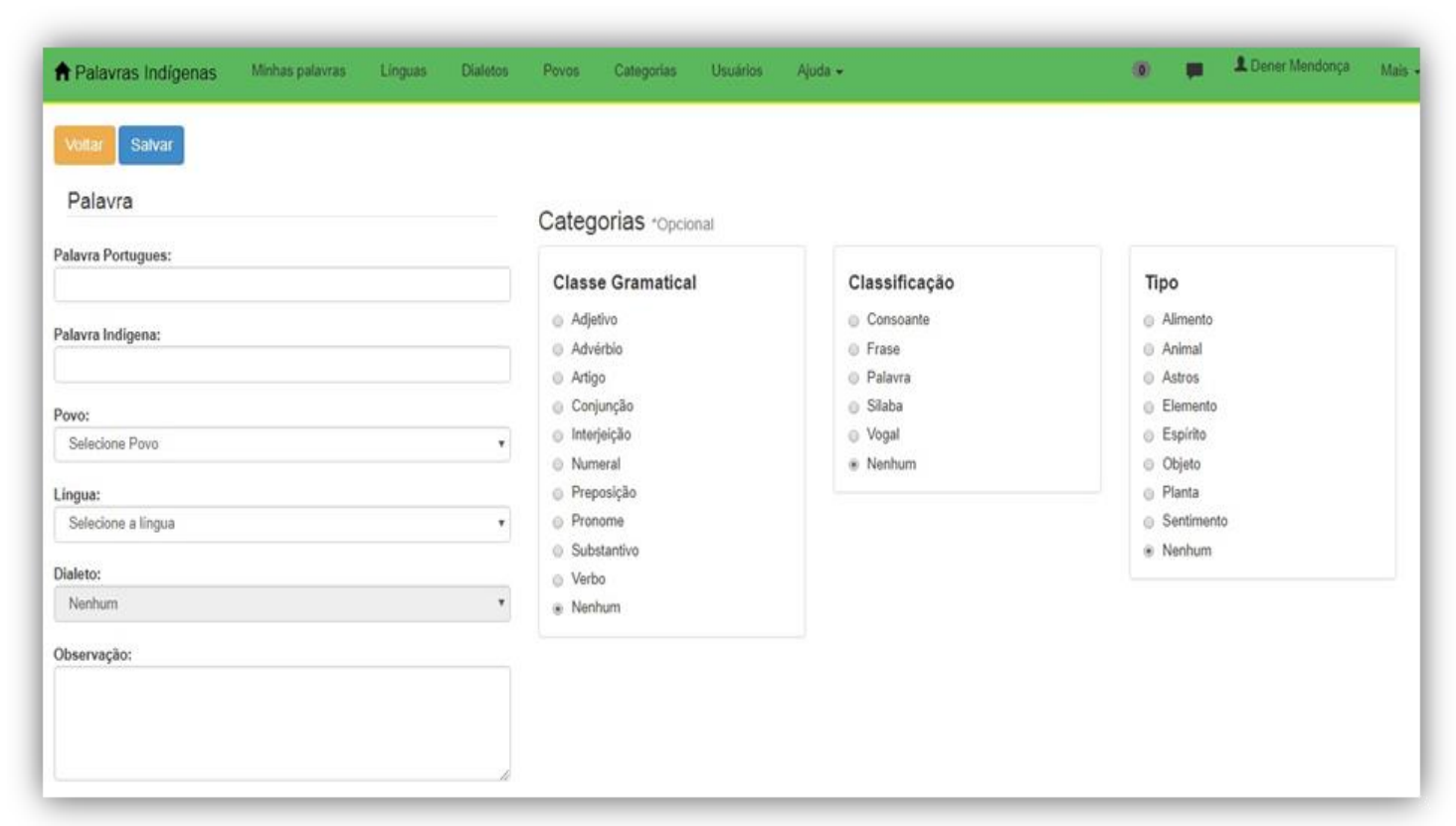

Figura 2. Tela de cadastro das palavras indígenas.

No cadastramento são preenchidas as seguintes informações: palavra (escrita) em português, palavras (escrita) indígena e selecionada a categoria a qual a palavra cadastrada se enquadra. A categoria é utilizada para classificação e busca na Tela Inicial do sistema (filtros) e posterior geração de um PDF com as informações filtradas. Apenas mediante o cadastramento das informações em texto é liberado a tela de 
VIII Congresso Brasileiro de Informática na Educação (CBIE 2019)

Anais dos Workshops do VIII Congresso Brasileiro de Informática na Educação (WCBIE 2019)

cadastro da imagem (jpg) e do som (mp3) que será vinculada a palavra cadastrada. Para inserção da pronúncia no Sistema Palavras Indígenas o som deve estar previamente gravado. O cadastro da imagem e do som é opcional. A Figura 3 apresenta a Tela de cadastro da imagem e do som.

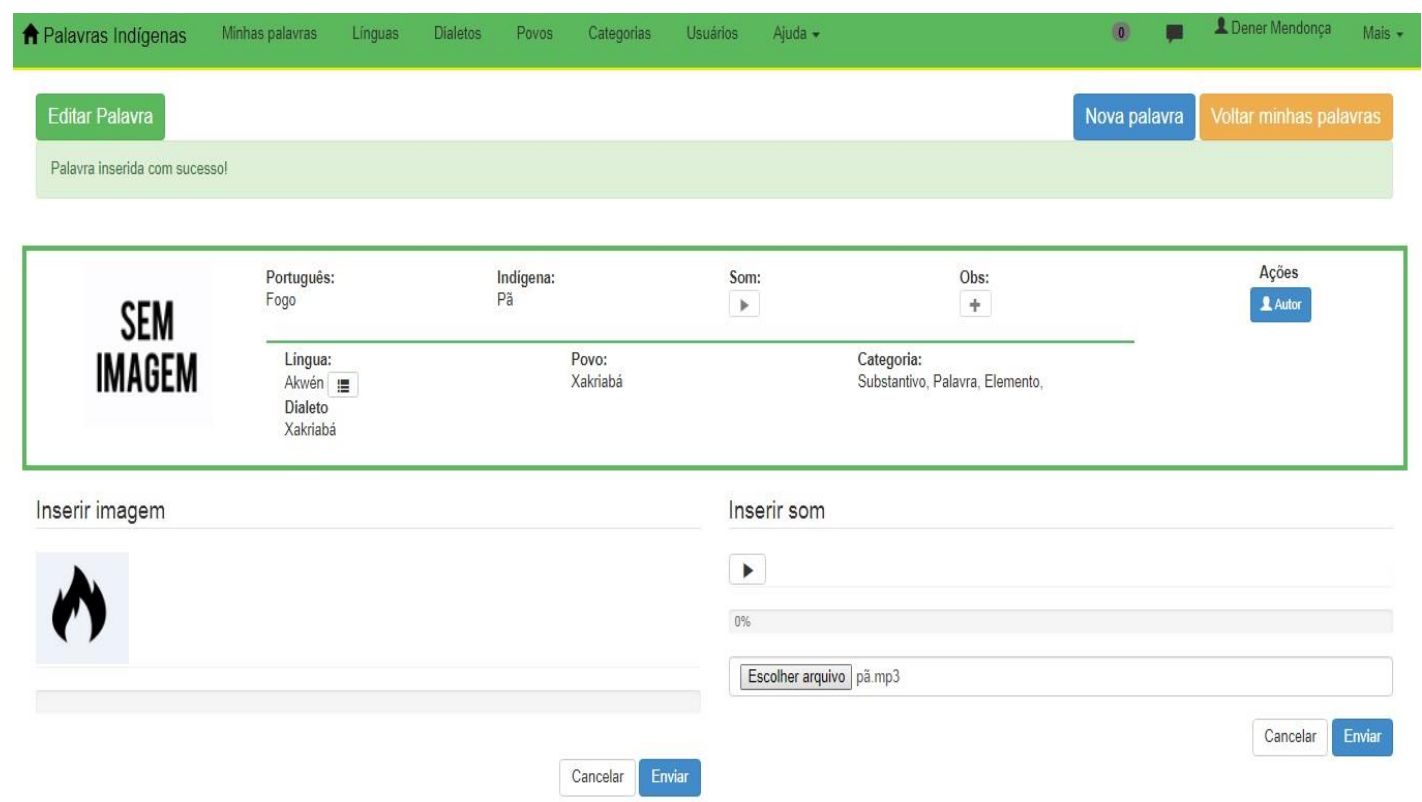

Figura 3. Tela de cadastro da imagem e do som referente à palavra indígena (texto).

Depois de cadastrada a palavra, inserida a imagem e o som é possível visualizar todas as suas palavras cadastradas através da Tela Inicial ou Tela Minhas Palavras. A qualquer momento é permitido alterar as informações cadastradas. Com os dados catalogados e armazenados, tem-se uma base de dados que possibilita a busca pela palavra desejada. O sistema está acessível na web no endereço eletrônico www.palavrasindigenas.com.br. Vale ressaltar que o Sistema Palavras Indígenas está sob a licença de Software gratuito (freeware) cuja definição é seu uso sem pagamento de licenças, entretanto seu código não é aberto. Não é permitida sua aplicação comercial, modificações e ou redistribuições sem prévia autorização. No link https://youtu.be/t-PZpvZJ1C8 é possível ter acesso ao vídeo demonstrativo do sistema.

\section{Considerações finais}

O uso da tecnologia no resgate, preservação e compartilhamento de línguas indígenas pode ser um importante instrumento de auxílio no fortalecimento das culturas indígenas frente à globalização. O sistema apresentado utiliza diversas modalidades de mídia (texto, imagem e som) para fornecer ao usuário uma navegação rápida, amigável e construtiva na medida em que cadastra as palavras indígenas existentes nas comunidades indígenas estabelecidas no Brasil.

Considerando os resultados obtidos pode-se concluir que, de acordo com os objetivos definidos, principalmente no que se refere à intenção de propor um sistema que ofereça subsídios para a catalogação e preservação das línguas indígenas, tais propostas foram alcançadas. Muitas são as possibilidade existentes para a continuidade deste trabalho, tanto do ponto de vista das funcionalidades do sistema (programação) 
VIII Congresso Brasileiro de Informática na Educação (CBIE 2019)

Anais dos Workshops do VIII Congresso Brasileiro de Informática na Educação (WCBIE 2019)

como pesquisas e questionamentos que podem ser levantados com a continuidade deste projeto.

\section{Referências}

Escobar, Suzana Alves. (2012). "Os projetos sociais do povo indígena xakriabá e a participação dos sujeitos: entre o "desenho da mente", a "tinta no papel" e a "mão na massa". Pós-Graduação em Educação: Conhecimento e Inclusão social." Universidade Federal de Minas Gerais - Faculdade de Educação. Belo Horizonte.

Gil, Antonio Carlos. (2008). "Métodos e Técnica de Pesquisa Social”. 6. ed. Atlas. São Paulo.

Jung, C. F. (2004). Metodologia para pesquisa \& desenvolvimento: aplicada a novas tecnologias, produtos e processos. Rio de janeiro: Axcel Books.

Mendonça, D., G.; Lima, J., F.; Gusmão, C., A.: (2015a). O uso da tecnologia no auxílio à preservação do idioma indígena: o caso Xakriabá. In Anais do XXXV Congresso da Sociedade Brasileira de Computação (CSBC). $4^{\circ}$ DesafIE - Workshop de Desafios da Computação Aplicada à Educação, Recife-PE.

Mori, Marta de. (2002). "Um Modelo de Tecnologia da Informação para Suporte à Administração Tributária Estadual.” Florianópolis-SC.

Oliveira, Djalma de Pinho Rebouças de. (2002). "Sistemas, organizações e métodos: uma abordagem gerencial”. 13. ed. São Paulo.

Scrócaro. Rúbia. (2013). "Elementos de Sustentação da Efetividade do Uso da Certificação Digital em Aplicaçãos de Internet Banking - Estudo de Caso em uma Instituição Bancária". Brasília-DF 